\title{
YUNAH LEE
}

UNIVERSITY OF BRIGHTON, UNITED KINGDOM

\section{Fashioning tradition in contemporary Korean fashion}

\begin{abstract}
This article reconsiders the debate of 'self-orientalization' in Asian fashion within the context of contemporary Korean fashion and its place in the promotion of the national economy and culture through distinctive national images and identity. Case studies of Korean fashion labels such as Tchai Kim and Isae reveal that they have challenged the typical images of hanbok, the traditional Korean dress, and provided styles and brands that resonate with local Korean characteristics as well as global fashion concerns. By reinterpreting traditional shapes and purposes of hanbok, employing traditional dressmaking methods and craft skills, and cleverly presenting and promoting their products and brands, these fashion companies have created a hybrid design and style. This has been built from the development of complex and mutually reinforcing interactions between local and global fashion knowledge and practice. This article argues that these new movements in contemporary Korean fashion provide further understanding of the complex and multifaceted dialectics of Korean fashion, beyond the dichotomy of tradition versus modernity.
\end{abstract}

\section{Keywords}

Korean fashion

self-orientalization

national identity 
globlization

tradition

hanbok

Tchai Kim

Isae

In the special issue of the International Journal of Fashion Studies that focuses on national identities, Jennifer Craik and M. Angela Jansen (2015) discuss the increasing scholarship on fashion and dress in non-western regions in order to counter the prevailing Eurocentrism in the study of fashion. The role of tradition and modernity in the process of constructing national identities receives particular attention. Craik and Jansen state that '[f]ashion designers are increasingly branding their national heritage/tradition as a successful marketing tool, while simultaneously reinventing/modernizing it' (2015: 4), in order to distinguish themselves in global fashion markets and establish alternative local fashion that counters homogenizing global fashion influences. This article reflects on this new approach to fashion dress history and to new developments in local fashion markets by focusing on the local specificity of Korean fashion within the global fashion system in two Korean fashion brands, Tchai Kim and Isae. Both brands have appropriated and modernized Korean tradition by addressing global fashion issues such as the meaning of national identity in fashion in a globalized world and ecological and sustainable fashion practice since the turn of the twenty-first century. ${ }^{1}$

Tchai Kim, established in 2013 as a ready-to-wear brand of Tchai Kim Young Jin (a handmade hanbok brand), has made its name with clothes directly and indirectly inspired by the shapes and colours of hanbok, the traditional Korean dress. The 
designer Young-jin Kim is one of the key figures in the creation of exclusive couture hanbok fashion. Kim and her hanbok have been featured in numerous high-end magazines such as Vogue Korea and My Wedding, which have brought her highly styled, contemporary aesthetics of 'fashion hanbok' to wider public attention. Tchai Kim's young, feminine and romantic style based on the fusion of traditional and modern fashion elements has particularly attracted fashion-conscious, affluent young Korean women in their twenties. Cheollik dress, the most popular item of Tchai Kim that made the brand's name, was very quickly copied by other hanbok makers and spread through popular fashion at more affordable prices. Isae FnC, established in 2005 by Kyeong-a Jeong, is a fashion company that established itself as a leading brand in the Korean sustainable fashion market by interpreting traditional Korean aesthetics and values from modern perspectives, particularly by concentrating on sustainability and ecological issues. Isae's modern, comfortable and modest style and its use of naturally dyed textiles have been noticed and adopted by consumers, mostly middle-aged women between their thirties and fifties who are looking for an alternative fashion style. Although the consumption of these two brands and the consumers' reception deserves a thorough exploration, this article will focus on the production of fashion designs and the development of brand identities by both Tchai Kim and Isae. Interviews that I conducted with both designers, Young-jin Kim and Kyeong-a Jeong, and visits to Kim's studio and Isae's design studio in 2016, were especially useful in order to gain new insight into their practices.

The design and branding of Tchai Kim and Isae share an interpretation and appropriation of traditional Korean forms, aesthetics and craft skills from contemporary perspectives. They differ, however, in the way in which they operate. Tchai Kim is relatively small in its revenue scale but extremely prominent in its 
fashion profile and targets a niche market of young, affluent, fashion-conscious women. Isae is a sizable company with over 200 retail outlets nationally, but its profile in fashion is deceptively low and its consumers are mostly middle-aged women who are interested in alternative fashion and lifestyles. By examining the design practice and branding of these companies through analysis of products, promotional materials and interviews with the designers, this article aims to provide an understanding of the ways in which Korean traditions are employed in contemporary dress and fashion. It will further evaluate the value and meaning of tradition within contemporary Korean fashion from the critical framework of global/local fashion debates.

With the global domination of western-style dress since the twentieth century and the homogenization of everyday clothing, ethnic dress has become associated with traditional dress, with symbolic association to local and to national tradition. On the other hand, unique local identities in fashion with a strong relation to ethnic and national traditions have been nurtured for the preservation of national cultural identity and appropriated in the establishment of national fashion industries. Debates on orientalism in fashion by western and European designers and the self-orientalizing process in Asian fashion are pertinent to the examination of mobilizing tradition, especially the appropriation of hanbok, the distinctive traditional Korean dress, and the promotion of the new fashionable hanbok as a Korean cultural product. The designs, the ethos behind the styles and the branding strategies of Tchai Kim and Isae reveal how Korean designers address this issue in the South Korean context.

\section{Hanbok as traditional Korean dress}

Korean fashion has gone through enormous changes during the twentieth century since the introduction of western styles of clothing in the late nineteenth century. The pace 
and scope of the changes was so decisive and encompassing, especially during the periods of rapid industrialization and urbanization of the 1960s and 1970s, that a ubiquitous western style of clothing was established as the everyday sartorial choice for Korean people in the latter part of twentieth century. In the late twentieth and early twenty-first centuries, hanbok largely remains a dress for special occasions, such as weddings, funerals and ceremonial rituals, symbolizing a distinctive Korean tradition and heritage, while contemporary Korean fashion has been subject to the strong influence of western fashion trends. The dichotomy of traditional versus contemporary, special versus everyday, in Korean fashion and dress has been a continuous source of discussion when considering contemporary meanings and purposes of hanbok.

This dichotomy between traditional and contemporary dress is also reflected in the study of Korean dress and fashion. Most academic studies of the history of Korean dress have focused on dress before the twentieth century, with a particular emphasis on the development of traditional forms by meticulously examining textual, pictorial and material evidence. ${ }^{2}$ With growing scholarship on the history of Korea in the early twentieth century, the emergence of modern western styles of clothing in Korea and changes to existing Korean dress have also been investigated (Ahn 2009: 250-70; Yu 1991: 337-70). Most of this scholarship established two separate types of clothing, Korean (hanbok) and western (yangbok), worn from this period onwards. Westernstyle clothing (yangbok) was adopted for governmental official wear by King Gojong of the Joseon dynasty at the end of the nineteenth century and was gradually incorporated into Koreans' everyday dress along with the wider introduction of modern western ideas and culture during the early twentieth century. By the end of the 1930s, yangbok was worn more widely, carrying the symbolic notion of modernity and modern culture, and was especially favoured by 'modern girls' and 'modern boys' in 
urban areas. Korean dress (hanbok) was, however, still worn by the majority of the population. Although the forms and shapes of hanbok went through alterations and modernization in response to new ways of life that were introduced through encounters with other cultures, mostly those of Japan and Euro-America, the basic composition of hanbok remained unaltered: for women, a short jacket (jeogori) and a long skirt (chima) and for men, a jacket (jeogori), a pair of trousers (baji) and a long coat (durumagi). It was not until the late 1960s and early 1970s that hanbok firmly obtained the status of 'traditional', as western styles of clothing prevailed as everyday dress (Kim et al. 2005). Just as the kimono was established as traditional Japanese dress in relation to the 'other' satirical expressions that had been adopted by the Japanese since the late nineteenth century (Assmann 2008), the meaning of hanbok was redefined as traditional Korean dress in relation to the adoption of the 'other' western style of clothing.

Throughout the latter part of the twentieth century, women's hanbok as traditional dress for special occasions largely kept the basic composition of a long and wide skirt and a short jacket with varied colours and embellishments according to trends. But, even as hanbok became a special Korean costume excluded from contemporary everyday fashion, there have been various attempts to keep the tradition of hanbok relevant to contemporary Korean fashion. On one hand, the ethnic characteristics of Korea (traditional shapes, forms, lines, colours, patterns) have been explored and appropriated by Korean fashion designers. For example, the so-called Arirang dress, designed by Korean fashion designer Nora No for Miss Korea's entry in the Miss Universe Competition of 1959, was supposedly adapted from several traditional elements from the Hwarang dress of the Shilla dynasty and from the nineteenthcentury hanbok, appropriating them in a western-style evening dress (Ministry of 
Culture and Tourism 2001; Kim 2001). On the other hand, the forms, shapes and colours of traditional hanbok were modernized and reformed in order to increase the functionality of hanbok and to revitalize traditional aesthetics and values for a contemporary sensibility. Since August 1961, when a government-sponsored campaign was launched to promote new styles of modest and practical dress for everyday wear, newly modernized hanbok designs were showcased in several promotional shows and publicized in newspapers and women's magazines (Fig. 1). Most of the 'reformed hanbok' (gyeryang hanbok) were, however, criticized due to the perceived inauthenticity of the hybrid design and materials, and they were shunned by the public. The position of hanbok as a beautifully made occasional traditional dress with a lavishly decorated, long and wide skirt was too firmly established.

Fig 1 Gyerang hanbok shown in the fashion show 'Modernism of hanbok' in Yeowon, August 1963, Seoul National University Library, Seoul.

During the 1980s, the rediscovery and preservation of Korean traditions became a critical and political strategy that the Korean government pursued in preparation for two international sports events, the Asian Games in 1986 and the Olympics in 1988. At one end, luxurious high-end hanbok for special occasions and high-profile events were made from various colourful fabrics with exquisite traditional decorations such as embroidery and gold and silver stencils (Fig. 2). In opposition to this, the authentic shapes and colours of hanbok were reconsidered to create something more simple and natural, shedding the excessive decorations of ritual hanbok. Korean folk tradition and the everyday culture of the peasant were especially explored as alternatives to the royal tradition of Joseon, notably by groups such as Jilgyeongyi, a civic association of university students and liberal intellectuals who have campaigned 
for wearing Korean clothes since 1984 (Yeom 2001: 195). They proposed and presented simplified and modernized hanbok designs, with a shorter and narrower skirt and a longer jacket with narrower sleeves for improved practicality, in muted earthy colours using traditional natural dyes (Fig. 3). These movements developed 'everyday hanbok' (saenghwal hanbok), which contributed somewhat to the popularity of hanbok as everyday wear. The popularity of these hanbok, however, was still limited to certain groups of people (students, intellectuals, activists) or an area of the tourist industry (often as staff uniforms), and failed to establish a meaningful alternative dress to everyday western-style clothing. General public perception of saenghwal hanbok was influenced by a strong political and ideological symbolism related to either radical social movements such as feminism or unionism or to official government promotion of traditional culture (Yeom 2001; Ruhlen 2003). Aesthetically, the general public was not excited by the simplified and muted appearance of saenghwal hanbok. It was regarded as rather drab due to the lack of variety in colour and shape, and the hybrid nature of the design was considered neither authentic nor modern enough.

Fig 2 Ree-ja Lee (designer), Hanbok with crane embroidery, 1990s, National Folk Museum of Korea. Courtesy of National Folk Museum of Korea, Seoul.

Fig 3. Display of saenghwal hanbok at The Exhibition of Image of Hanbok and its Globalization, 1998, National Folk Museum of Korea. Courtesy of National Folk Museum of Korea, Seoul.

\section{Korean fashion from the 1990s: Tradition, globalization and orientalism}

Another avenue for exploring Korean tradition can be found in the major review of Korean style and tradition in dress that began in the early 1990s with the slogan 'What is Korean is what is global' ${ }^{3}$. Traditional Korean elements, techniques, materials and crafts were physically and conceptually incorporated, reworked and expressed in the 
work of a number of Korean fashion designers. This reworking, or appropriation, of traditional dress needs to be discussed in the context of globalization. The term 'globalization' began to appear on the South Korean political and economic agenda from the early 1990s, against a background of aggressive advancement of international capitalist free market policies by Euro-American countries (Globalization Committee 1998; Gu 1996). A determination to increase South Korean trade and economic competitiveness and to raise the status of South Korea in the world was officially declared in the South Korean government's policy for 'globalization' in 1994. For this globalization campaign, the discussion of the role of design in South Korean industries was brought forward in the context of design reform and good design debates. Another aspect of this discussion was the debate on what constitutes Korean national identity, 'Koreanness', and how a multiplicity of national identities could be developed and expressed in various areas of culture under the slogan 'What is Korean is what is global'. This quest for authentic Korean culture and style in relation to globalization has been a reoccurring theme of Korean dress and fashion (Jeong 2000; Kim, Min-ja 2009; Lee 2009). As Eugenia Paulicelli and Hazel Clark (2009) state, in order to produce its own vision of fashion and design, a country goes through 'the process of reinventing and reusing their own tradition and "national fabric" [...] This process also entails a re-examination and rereading of one's own nation's history [...] Fashion is an open window through which to observe such phenomena' (Paulicelli and Clark 2009: $3)$.

The process of globalization in Korea since the early 1990s created a two-way traffic of fashion exchange; not only were the major Euro-American fashion brands imported, directly competing with the South Korean brands, but also a handful of Korean fashion designers, including Young Hee Lee, Cinu Lee, Jin Te Ok and Sang 
Bong Lie, took the initiative by showing their collections in Paris (Lee 2009; Kim 2006; Kim 2001). The collections presented by Cinu Lee, Jin Te Ok and Sang Bong Lie were western in style but incorporated elements of traditional Korean art and culture, including the lines and shapes of hanbok, the pattern and colours of Korean architecture known as dancheong, the form and technique of Korean wrapping cloth bojagi, and Korean alphabets (Hangul) and calligraphy. Young Hee Lee's collection was different from the rest, representing the possibility of appropriating hanbok in contemporary fashion, based on her long experience of making hanbok. For example, the long skirt of traditional hanbok was shown in Paris in 1996, worn as a strapless evening dress without a jacket. The exquisite long flowing silhouette of traditional Korean silk in arrays of colours earned the dress the title of 'costume du vent' (Lee 2008). Both Korean and international fashion critics discussed the work of these designers in terms of aesthetic and conceptual translations of 'Koreanness', with an emphasis on traditional forms, colours, prints, materials and techniques (Kim 2008; Kim, Min-ja 2009). With government support for promotional activities, hanbok was established as one of the key cultural assets to be developed into a cultural product such as fashion. Young Hee Lee's hanbok design demonstrated this potential to a younger generation of hanbok makers and designers.

Since the early 2000s, there have been further significant changes in the design and styling of hanbok. This latest trend is especially noticeable in the contemporary changes to the traditional Korean wedding dress. While some designers have been focused on rediscovering and perfecting the traditional forms and crafts of the precolonial period (before 1910), others are revisiting and reconsidering traditional forms, materials and styles from contemporary perspectives and with modern sensibilities, creating extremely hybrid forms and ideas of Korean dress. Equally as notable in this 
process of re-evaluation and re-creation is the representation of hanbok in fashion photography, often featured in Vogue Korea and wedding and lifestyle magazines and also in the popular media, especially blockbuster period dramas and movies. The new hanbok and its representations interpreted the traditional hanbok through the eyes of western aesthetics and fashion languages and repackaged it as a desirable and luxurious fashion. As such, they are as refreshing and innovative in establishing new fashionable images of hanbok as they are nostalgic and predictable in retaining established notions of Korean dress, and also of oriental women more widely. The ambiguity and complexity, however, of orientalizing and self-orientalizing processes in Asian fashion are also worth considering in order to further understand the interpretation and appropriation of hanbok in contemporary Korean fashion.

The highly styled images of women in hanbok reflect the disturbing development of orientalizing Asian fashion within Asia, recycling exoticized and sexualized images of Asian women cultivated by the western gaze, as observed by Sandra Niessen, Ann-Marie Leshkowich and Carla Jones in the edited collection ReOrienting Fashion: The Globalization of Asian Dress (Niessen et al. 2003: 26-29). This argument is also true for a number of fashion editorials and features promoting a Korean/oriental look in Vogue Korea, which are regularly seen in its pages since its launch in the Korean language in 1996. Features such as 'Mist from the Morning Calm' (January 1997), 'Eastern Chic' (August 1997) and 'Oriental Express' (February 1998) present the work of Korean designers demonstrating the characteristics of Korean culture in its patterns and decorations. The overall effect, however, creates rather ambiguous and ambivalent imagery conveying distinctly hybrid ethnic notes and familiar exoticized western ideals of the Orient. This phenomenon is clearly found in the cover image of Vogue Korea in June 2007. It featured a well-known Korean 
actress, Hye-gyo Song, as the famous Korean gisaeng (geisha), Hwangjini. It received attention from the media, firstly because it was the first Vogue Korea cover to feature a Korean woman, and secondly because the images of Song and Hwang were quite distant from the conventional image of Korean beauty. In the photograph, Song wore a hanbok skirt designed by Gu-ho Jeong but the dress was barely visible and the focus was very much on her turned face and bare back. The make-up and hairstyle created an image of the exotic and haunting beauty that was ambiguously oriental. It was photographed by Paolo Roversi in Paris with the assistance of an international crew of stylists. The composition and effect of the image are compatible with Roversi's photograph of a young Natalia Vodianova, published in Vogue Italia in September 2004. It is possible to conclude that this image is not necessarily about Korean women (Song/Hwang) or about Korean dress. The author of this photograph is clearly Roversi, who cast a European gaze over the interpretation of Korean dress and beauty, revealing the domination of western aesthetics and ideology over the local in global fashion cultures.

The story, however, can be slightly different when we consider the stylistic direction of the movie Hwangjini (2007), directed by Youn-hyun Jang. In comparison to the ravishing colour of the hugely popular 2006 TV drama of the same title, Jang's movie is more subdued in the composition of its cinematic frames and the styling of the dresses and make-up, and it uses an ambiguously hybrid creativity to skirt inbetween the traditional and the modern/contemporary. Roversi's photographs in Vogue Korea also fit this aspect of Korean creative output, a point that was not picked up in most of the criticism of the Vogue cover. What we observe here is the complex and nuanced way in which orientalizing and self-orientalizing in Korean fashion occurs. The hanbok that have appeared regularly in fashion features since the 2000s 
demonstrate experimental styles through the creative and unusual juxtaposition of garments (both hanbok and non-hanbok) and accessories, producing an oriental or Asian look with a hint of Koreanness. What is important to consider here is that Korean designers, editors and photographers working in the fashion industry are versed in what is expected to be the distinctive nature of Korean/Asian fashion and postmodern approaches of borrowing and mixing different stylistic elements for fashion creation. As Leshkowich and Jones (2003: 281-82) explain, criticism of the socalled Asian chic trend as an orientalist practice perpetuated by the western fashion industry is a valid point to consider. However, while Asian chic repeats and satisfies the West's vision of Asian fashion in many ways, the deliberate self-orientalizing process and mimicry of Asian designers and consumers may be intentionally challenging and 'countering oriental stereotypes'. This is 'open[ing] up a critical space that exposes the contingent foundation of Orientalism' and 'could be an empowering move, an attempt to reclaim the authority to define the meanings associated with a style or aesthetic element' (Leshkowich and Jones 2003: 285). They continue that the ambivalent and ambiguous nature of self-orientalization needs to be examined in regard to who performs this process, and what the intentions and personal and political effects of these choices are: 'Self orientalising can be a privilege that enhances the status of those who employ it by signalling their familiarity with the global discourse of fashion' (Leshkowich and Jones, 2003: 285). Hazel Clark discusses this point in the context of Chinese fashion and argues that the new 'China style' that emerged in the early twenty-first century in the cases of Shanghai Tang and Blanc de Chine demonstrated the evolution of an ethnic fashion from self-orientalization to the provision of a new way of dressing that challenged dominant western fashions (Clark 2009). 
Applying this argument to the case studies of two Korean fashion brands, Tchai Kim and Isae, I suggest that both brands demonstrate how the seemingly selforientalizing process in Korean fashion needs to be considered as a deliberate strategy to establish distinctively Korean brand identities in order to compete against the domination of global brands and styles in Korea. This article further argues that the popularity and success of both brands are to be understood within the wider frame of nationalism and the promotion of the national economy and culture in recent Korean history. Segre Reinach observed that national identity became more important in globalized fashion production and consumption: 'Each nation has a vested interest in being recognized as a place of creativity and aesthetics [...] Fashion itself is $[\ldots]$ the chance for countries to take part in the global exchanges, the interconnections making our period' (Segre Reinach 2011: 268-69).

For the last couple of decades, there has been a steady and significant growth in the interests and finances poured into the promotion of hanbok. Investment in hanbok has been part of the Korean government's promotion of Korean culture that capitalizes on the 'Korean Wave' (hanryu), the fervent consumption of Korean popular culture such as K-pop and K-drama, especially in Asia. Government promotions have included the establishment of the Hanbok Advancement Centre and Hanbok Day, organizing hanbok fashion shows and competitions (Hanbok Advancement Centre 2015). This is related to an emphasis on traditional crafts and craftsmanship and national pride; however, ultimately it relates to the development of a heritage industry and tourism for both Koreans and foreign visitors. In this context, hanbok and fashion inspired by hanbok has become an important cultural product of Korea. The following case studies of Tchai Kim and Isae position them at the forefront of this development. 


\section{Tchai Kim: Reinterpretation and branding of Korean tradition}

Young-jin Kim established a traditional custom-made hanbok brand Tchai Kim Young Jin in 2004, and launched the ready-to-wear brand Tchai Kim in 2013. Tchai in Korean means difference, which is stated as the philosophy of the brand: 'the difference in sensibility makes the difference in clothes' (Tchai Kim 2016). How is her hanbok different and what does she mean by different sensibilities? In numerous articles about Kim and her designs, based on interviews with Young-jin Kim (Kim, Min-hui 2009; Bak 2013; Jo, Yu-mi 2013), Tchai Kim's hanbok are known for a new style and contemporary creative interpretation of traditional hanbok, inspired by the proportion, line and shape of the hanbok shown in Portrait of Beauty (Miindo), the famous eighteenth-century painting by Yun-bok Shin. The credibility that she gains through her understanding of traditional materials, skills and crafts is derived from her short but important period of needlework tutelage in 2003, under Kwang-hyeon Bak who carries the title of chimseonjang, the official intangible cultural asset of needlework. Tradition as a source of design inspiration and knowledge of traditional craft skills are commonly mentioned by other established contemporary hanbok designers such as Hae-soon Kim, Yeong-ju Baek, Yeong-jin Bae and Yeong-gi Jo. What makes Youngjin Kim stand out from the crowd is the unusual use of a wide range of fabrics from the traditional ramie and silk of the Sangju region to luxury fabrics such as high-end French lace and the English Liberty patterned cottons, and striking and unexpected colour palettes.

This juxtaposition of tradition and modernity and the Korean and the foreign is featured in magazine articles about Young-jin Kim's design of hanbok, and is seen in the ways in which Kim is portrayed in her own hanbok dresses (Kim, Min-hui 2009) and the interior design of her studio (Jo, Yu-mi 2013). This juxtaposition is also clearly 
evident in the styling of hanbok on the pages of Vogue Korea in the 2000s, and items by Tchai Kim Young Jin have featured regularly in editorials and feature articles, often in a highly styled fusion of traditional and modern fashion sensibilities. Kim's modern sensibilities are evidently situated in both being a Korean and a global citizen, especially thanks to her unusual background in making costumes and props at the Korean dance theatre in the early 1990s before embarking on a career as a buyer and manager of the European luxury brands Cerruti 1881 and Louis Vuitton in Korea (Kim 2016). She emphasizes the importance of knowledge and appreciation of materials and the value of good-quality fabrics in the making of luxury fashion, which continues to be one of the most important aspects of her design. For example, a sophisticated and intricate effect is created by layering lace over traditional Korean silk, achieving a different look yet using traditional hanbok fabrics (Fig. 4). In her own words, she has been creating hanbok that reflect her modern tastes: 'eating kimchi but also enjoying wine too' (Kim 2016, author's translation).

Fig 4. Tchai Kim Young Jin, Hanbok jeogori in various textiles, Seoul. Author's own photograph, 2016.

Another aspect of Kim's practice that distinguishes her from other high-end hanbok makers is her attitude towards the division between the design and production of a dress. Traditionally, needlework was a woman's most important skill, which required many years of practice, and one person's hands would carry out both the designing and the making of a garment. When asked about this, Young-jin Kim identified herself as a hanbok designer, not a maker, clarifying that she contracts out the sewing and needlework to highly skilled seamstresses in a craft studio. 
Hanbok [production] needs to be divided amongst separate people - a designer, a

sale's consultant dealing with customers, and an artisan who sews and completes the needle work. It is okay for a designer to deal with customers as a sales consultant but s/he doesn't need to carry out the sewing. Did Chanel sew all her garments? No, she didn't. Perfectly functioning craft studios are essential for the materialization of the visions/designs into a dress. (Kim 2016, author's translation)

It is likely that her rather unconventional path into the hanbok business and a short period of learning needlework conditioned her method of design and making. The design board on the wall of Kim's studio with her design sketches, sample fabrics and other images that inspire her work shows her design process rather than the physical making and sewing. She insists that although substantial knowledge of the quality of the materials and skills is important in design, both respect for the skilled craft of needlework and professionalism in separate areas of hanbok production are essential to her operation. She also extends this view to the area of the representation of hanbok in fashion photography, fashion shows and exhibitions, valuing collaboration with stylists and photographers, especially with Young-hee Seo, the highly sought-after stylist who has worked with Kim on numerous projects. This understanding of fashion design, production and representation is one of the most crucial factors of her success in establishing the most fashionable high-profile hanbok brand of the early twenty-first century.

Young-jin Kim's ready-to-wear brand, Tchai Kim, was launched in 2013 and aimed to create a fashion brand beyond the hanbok market, providing clothes that 'blend in beautifully' with modern ready-to-wear. It reflected Kim's confidence in further experimentations with traditional hanbok, developing loose links to tradition and creating designs of a more hybrid nature. In an interview, Kim expressed more 
ambiguous feelings about the conventional idea of hanbok as the essential and authentic ideal of Korean national dress, and commented on inter-Asian influences in the development of sartorial practices in Asia, in particular between China, Korea and Japan. According to the company's promotional literature, their distinctive and popular items are reinterpretations of the traditional hanbok, creating 'comfortable and practical clothes that can be worn everyday' (Tchai Kim 2016). They include

cheollik dress, the dapo coat, daegeumhyeong jacket, the jeogori jacket of the Kim family of the Yeonan region, the jeogroi jacket of the Kim family of the Suncheon region and the baenet jeogori inspired by the traditional bowless jacket for newborns. (Tchai Kim 2016)

Rooted in history, Tchai Kim 'offers styles that are beautiful, contemporary and global' (Tchai Kim 2016).

So what makes the style of Tchai Kim 'beautiful, contemporary and global'? Tchai Kim clothing is made with good-quality natural fabrics such as linen, cotton and silk, mixed with synthetic materials. Like Kim's couture brand, 'a note of originality and subtlety' is added through the use of unexpected materials, such as lace and floralpatterned cotton fabrics, delicate finishing details and a beautiful range of colours and hues. The cheollik dress, the most popular Tchai Kim item (see Fig. 5), materializes the new and original interpretation of traditional hanbok in various ways. Cheollik was a traditional garment worn by men during the Joseon dynasty. Although there were variations in its length and width, the essential features of the traditional cheollik are a closed neckline, a jacket with side-ties and a pleated skirt below the waistline connected to the jacket (Fig. 6). Inspired by Yoseon cheollik with fitted bodice, cheollik dress has been created as a one-piece wrap dress for women. It feminizes the line and shape of the traditional garment with an accentuated waistline for the female body. 
Repurposing and reinterpreting traditional men's clothes for women's clothes is one of the common elements of contemporary hanbok design to which Young-jin Kim has contributed since the beginning of her career. Another popular item, the dapo coat, is also adapted from a traditional men's outer-layer garment and styled to be worn together with modern everyday clothes in order to create a casual look.

Fig 5. Tchai Kim, Heori chima worn over cheollik dress, 2014, tchaikim (2014), 'Comment: tchaikim mosi heori chima (soldout)', Tchai Kim, 6 June, http://blog.naver.com/tchaikim/220022174072, Accessed 13 September 2016, Courtesy of Tchai Kim.

Fig 6. Yoseon cheollik with detachable sleeves, Joseon Dynasty, National Folk Museum of Korea. Courtesy of National Folk Museum of Korea, Seoul.

Layering is another aspect of both traditional and contemporary dress. Dressing in hanbok traditionally required many different layers of innerwear and outerwear depending on the place and occasion. While Tchai Kim's design and styling reflects this traditional way of dressing, it also experiments and plays with the idea in different ways, by adding the layers in a different order or showing an inner garment on the outside. The layering of a skirt (heori chima) over a cheollik dress creates the silhouette of a narrow and fitted top with a voluminous skirt, which resonates both with the eighteenth-century hanbok line and the postwar European style heralded by Dior's New Look. Heori chima is a modern variation of the traditional skirt (for example, as seen in Fig. 2), shortened to a below-the-knee hemline. It is tied around at the proper waistline instead of over the breast in the traditional way. Made in beautiful colour ranges that complement the cheollik dress, the skirt-over-cheollik dress adds an overall effect of romantic femininity, which can be replicated with different combinations of colours and patterns. 
Another example of repurposing and layering is seen in Fig. 7, which illustrates an ensemble presented in 2017 (Fig. 7). The model is wearing a white jeogori shirt and a pair of dansokgot trousers in red. Dansokgot was traditionally made of undyed cotton or linen and was one of the many layers of underwear worn under a skirt. In Tchai Kim's new interpretation, it is repurposed as outerwear trousers in striking red. A jacket called a double-collared baenet jeogori is shown worn over the shirt and trousers. Baenet jeogori was a traditional jacket, often made for a baby out of undyed cotton or ramie. It had a round neckline and the front was loosely tied with short strings. The Tchai Kim jacket has been reconstructed as a long loose-fitting outer garment, showing only a trace of the tradition that inspired its design. The overall silhouette of the ensemble still resonates with the voluminous skirt-line of traditional hanbok but the stylistic effect of the Tchai Kim image is casual and contemporary with a touch of avant-garde fashion.

Fig 7 Tchai Kim, Double-collared baenet jeogori jacket over jeogori shirt and dansokgot trousers, 2017, tchaikim (2017), 'Comment: tchaikim 2017 Lookbook', Tchai Kim, 13 May, http://blog.naver.com/tchaikim/221004860833, Accessed 15 July 2017, Courtesy of Tchai Kim,

This pick and mix of different styles, eras and traditions represents a postmodern approach to fashion. Although fashion has been historically inspired and influenced by many different styles and trends, the adaptation and fusion of different styles and elements beyond their original historical and cultural contexts has been developed more deliberately with postmodern attitudes towards history and originality during the latter part of the twentieth century. Young-jin Kim explains that a different method was employed in designing Tchai Kim's clothing line: ‘Tchai Kim’s design looked at all kinds of clothes in the world including European romantic styles and 
collected the elements and features that are similar to those found in hanbok' (Kim cited in Bak 2013, author's translation). She found similarities of construction between the pleats of nineteenth-century European dress and those of cheollik skirts, and between the Spanish bolero and the jeogori jacket of the Kim family of the Yeonan region in the sixteenth century. In Kim's postmodern fashion practice, the traditional elements of Korean dress have become just one of the many fashion references and vocabularies that she draws upon for the creative expression of her fashion ideas. This is going beyond the self-orientalization of her own cultural traditions and reflects the designer's knowledge of the fashion system and her maturity and confidence in implementing design approaches and branding practices in order to create a unique brand beyond the limited traditional hanbok market.

\section{Isae: The ecology and sustainability of Korean tradition}

Isae was founded as Itbit (a Korean word for natural dye) in 2000. Since the new launch as Isae in 2005, the company has grown rapidly as the leading sustainable fashion company in Korea, creating a modern, simple line and naturalistic style. It received a Golden Award in the Ecological Fashion category of the Korean Fashion Association in 2009 and the company's revenue reached 3.5 trillion KRW in 2015. Compared with Tchai Kim's apparent roots in hanbok and tradition, Isae's interpretation of Korean tradition is more abstract and subtle with an emphasis on the traditional Korean attitude towards nature. The first catalogue of Isae, titled Philosophy - How to Make Clothes 2009-2010, placed concern for nature at the centre of its brand identity. The English text of the catalogue states: 'we love nature in its pure state. We make clothes capturing the purity, with light, wind and loving care' (Isae 2009). The photographs in the catalogue portray women in their thirties in natural surroundings, 
interacting with nature and emphasizing the harmony between human beings and nature (Fig. 8).

Fig 8 Isae, Philosophy - How to make clothes 2009-2010 Catalogue, 2009, Seoul: Isae. Courtesy of Isae.

Kyeong-a Jeong, the CEO of Isae, studied fashion design and dress history at the Kukmin University, Seoul, during the late 1980s. For her, the tradition of Korean cloth begins with the materials, and the traditional Korean philosophy of living in harmony with nature is essential for building an ecological and sustainable basis for Korean fashion (Jeong 2016). Her ideas about Korean tradition are rooted in the rediscovery of Korean tradition and heritage, and in her travels to historic cultural sites in Korea. This latter point has become an important cultural issue since the late 1980s, with the increased interest in a forgotten history of Korea which was pursued by liberal students and intellectuals. In this sense, Isae's clothes are in the same vein as saenghwal hanbok, worn with political and ideological symbolism in the 1980s. Jeong, in fact, worked in a company that produced such hanbok. She, however, distances Isae's garments from the negative image of saenghwal hanbok, and avoids limiting the brand image of Isae within the hanbok market.

Fig 9 Isae, Jacket with Jegori sleeves, 2012, Seoul. Courtesy of Isae.

The design of Isae's clothes is inspired by traditional hanbok shapes and patterns but reinterpreted and appropriated for the modern lifestyle, creating a loosely fitted, simple and natural look. For example, the rounded shape of traditional hanbok sleeves inspired a sleeve shape for a jacket that was patented for its innovative and modern pattern and improved practicality in 2011 (Fig. 9). ${ }^{4}$ This jacket has a mostly western 
construction with a nod to a traditional Korean element. More generally, attention to detail, the use of naturally dyed textiles and the employment of particular needlework techniques not only reflect traditional Korean dress production but also resonate with a recent emphasis on the value of the handmade in global branding as a new luxury in the rapid cycle of fashion production and consumption (Leadbeater 2012). The important value of women's sewing crafts is also recognized in the name of the brand, as a catalogue explains:

\footnotetext{
'Isae' is a pure Korean word referring to household chores, traditionally considered women's work. Sewing, in particular, was seen as a predominantly female trade. In that sense, the total fashion brand Isae is dedicated to the production of exquisite, soulful clothing and accessories that might be compared to the dexterous, knowing female touch to needlework. The sense of 'being home' created from all-national materials, sophisticated design in line with the modern fashion lexicon, and commitment to a quality finish - they are the ingredients for the chic elegance of Isae garments. (Isae
} 2009: 3)

The process of making is integral to Isae's brand identity, pursuing a slow and natural pace of production and consumption. Brief information about two kinds of Korean quilting techniques (nubi) is given on the company website, accompanied by a series of photographs of hands sewing the fabrics and details of the patterns created by the needlework (Fig. 10). Such dissemination of knowledge related to the skills and processes behind the designs via leaflets and the company website are thought to be important in terms of the transparency and credibility of a company's ecological claims, as well as in educating its existing and potential consumers. 
Fig 10. Screenshot of Isae official website, This page shows quilting process for making of a quilted jacket, Isae (n.d.) 'Process: Quilting of Cotton Wool', Isae: Urban life in nature, http://www.isae.co.kr/process/p_07.html. Accessed 26 August 2017.

At the centre of the ecological and sustainable ethos of the brand lies the importance of the materials and natural dyeing processes, which is elaborated on rather evocatively in a catalogue entry:

\footnotetext{
natural fabrics, like simple and resourceful cotton, austere yet elegant hemp, soft, warm wool, and chic, lustrous silk, do soothe your body and mind. Isae also employs all-natural dyeing, with ingredients that are readily obtained from mountains and plains, to deliver a beautiful colour palette. Jjok, the hue of the ocean; Gam (a persimmon), a touch of autumn richness; Meok, the soot of burnt pine trees; Ssuk (a mugwort), the vitality of its shoots breaking through the surface of the soil; and Hawngto (yellow ochre), a secret to good health. (Isae 2009: 4)
}

In an interview (Jeong 2016), Jeong talked about her long-standing interests in locally and naturally sourced materials, although such materials are not limited to Korea. Khadi, the Indian cotton fabric that was made into a symbol of Indian resistance and dignity by Gandhi, is easily spotted in Isae's catalogues. Clay-dyed fabric, the most popular and representative material of the Isae brand, is found in the southern region of China; since she first saw the material in a market in Shanghai, Jeong searched for three years before finding the source of this clay-dyed fabric in China. This anecdote demonstrates her dedicated efforts to discover naturally dyed and locally sourced materials, and the importance of communicating this to her customers. Information about the source materials and dyeing techniques along with care instructions for how to wash and store the garments are given in a small promotional card, the contents of which include details of the slow natural making processes involved in the garment's 
creation; the limited supply of materials; and the longevity of the garment if it is cared for well. The clay-dying process is also explained in detail. ${ }^{5}$ In addition, customers are advised to choose silk garments a size larger to usual, as the fabric has little elasticity, and to wear silk garments every other day (not every day) because they will be easily worn due to friction.

Although some earlier saenghwal hanbok companies in the 1980s and 1990s shared similar concerns and values, the wider recognition of ecological and sustainable fashion did not emerge until the mid-2000s in Korea, while interest in sustainability began in Korea during the late 1990s (Hong and Miwoo 2010; Yoo 2012). Isae has pushed forward the commercial potential of sustainable fashion by collaborating with the Korean High-Tech Textile Research Institution. It developed products utilizing more ecological and sustainable materials, such as kenaf-based textiles in 2010, and a cotton and modal textile made from the Cold Pad Baton dyeing process in 2013 (Jo, Byeong-min 2013).

Isae has thus been addressing global eco-fashion issues in relation to the reconfiguration and reinterpretation of tradition and traditional craft skills and through processes that require slow production and consumption and the appreciation of local/national tradition and heritage. This revival of the handmade in the world of design is a reflection of the discourse on the local in the global; for example, the emphasis on local tradition and characteristics; ecological concerns such as closed-loop material cycles; small-batch productions; and community spirit. The pull of craftsmanship towards fashion, nostalgia and morality certainly appeals to people's concerns about ethical consumption. The emphasis on craftsmanship, tradition and slow production and consumption in Isae's brand ideas is resonant with the recent promotion of 'process, heritage and quality' by global luxury brands, such as Gucci's 
advertising campaign featuring a black-and-white photograph of master craftsmen cutting leather in a workshop. In the recently revised meaning of luxury, handcrafted products which took time to make with care, becomes a luxury that allows us to restore relations with each other and nature in defiance of the frenzied pace of modern life (Leadbeater 2012: 9). Isae's interpretation of tradition and traditional crafts with regard to global fashion concerns illustrates another way of fashioning tradition beyond the negativities of self-orientalization in contemporary Korean fashion. It challenges the rather conventional representation and adoption of tradition found in saenghwal hanbok and brings these traditional values into the contemporary everyday fashion realm.

\section{Conclusion}

Analysing the deliberate strategies of fashioning tradition that were adopted by Tchai Kim and Isae demonstrates the ways in which they have challenged, interpreted and appropriated the conventional image and style of hanbok. The designers studied here have created fashion brands that incorporate global fashion aesthetics, approaches and concerns while resonating with traditional Korean characteristics and ethoses. Tchai Kim's young, hybrid and contemporary clothing style is the product of Young-jin Kim's postmodern and contemporary approaches to historical styles and hanbok. Kim's experience and knowledge of global fashion brands and systems have informed her design practice as a designer beyond the hanbok market. With the high visibility of the designer and her brands in Korean fashion, Tchai Kim has made a significant impact in bringing hanbok into the everyday fashion. Isae's modern and comfortable look is based on the ethos of the Korean tradition of living harmoniously with nature, which is ideologically aligned with global concerns of ecology and sustainability. Its 
emphasis on natural materials, traditional making methods and craft skills is shared with broader debates on slow and responsible production and consumption of fashion, and the concept of new luxury through time-consuming processes, local traditions and heritage. By cleverly presenting and promoting their products and brands, both Tchai Kim and Isae added cultural as well as financial value to their products and brands.

This article places the meanings of these Korean/Asian representations in the development and promotion of Korean fashion in the globalized market since the 1990s within the framework of critical debates on ambiguity and ambivalence in the 'self-orientalization' of Asian fashion and national/local identities in global fashion. Mobilizing and fashioning Korean tradition and ethnic style is "part of a global process in which identity is simultaneously experienced as "authentic" and as a unique selling point' (Craik and Jansen 2015: 4). On the one hand, this is the certainly the case in the design and branding of Tchai Kim and Isae. On the other, their creative and hybrid design and style has been built from the complex and mutually fertilizing interactions between local and global fashion knowledge and practice. The reinterpretation of ethnic tradition and the creation of a hybrid contemporary style, beyond the dichotomy of tradition versus modernity shown in the fashion products and branding of Tchai Kim and Isae, certainly helps to further understand the complex and multifaceted dialectics of contemporary Korean fashion in the local/global discourse.

The new movements in contemporary Korean fashion represented by Tchai Kim and Isae have moved in a further direction in the past decade, with the Korean government's promotion of Korean culture domestically as well as internationally since the beginning of the twenty-first century. In the midst of Korean traditions updated with new contents and images, hanbok has been reborn as distinctively Korean yet fashionable clothing that can be incorporated into everyday life. The popularity of 
this new fashionable hanbok, to which Tchai Kim and Isae have contributed greatly, has penetrated the popular market through TV costume dramas and movies showing attractive new hanbok designed by well-known designers, as well as the fast-and-wide circulation of fashion images. In addition, the recent trend of dressing up in fashionable hanbok for going out and posing for photographs in order to capture 'the moment-oflife (insaeng) shot' has been followed by young women and is producing a plethora of images on social media sites. It is a new and fascinating phenomenon that deserves further research.

\section{References}

Ahn, M. (2009), Uri ot iyagi: hanguk boksik munhwasa (The Story of Our Clothes: Cultural History of Korean Dress), Seoul: Yeohank-sa.

Assmann, S. (2008), 'Between tradition and innovation: The reinvention of the kimono in Japanese consumer culture', Fashion Theory, 12:3, pp. 359-76.

Baek, Y. and Choe, H. (1993), Hankuk-ui boksik munhwa (The Culture of Korean Dress), Seoul: Gyeongchun-sa.

Bak, E. (2013), 'Kim Young-jin, giseongbok brand Tchai Kim lonchinghan hanbok desaineo' ('Kim Young-jin, hanbok designer who has launched a ready-to-wear brand, Tchai Kim'), Design, October, http://mdesign.designhouse.co.kr/article/article_view/101/64205. Accessed 11 July 2017. 
Cheon, S. (2010), 'ije uiryu-edo chinhwankyeong-eul jeomokhal ttae-imnida: Isae creative director' ('This is time to consider ecology in fashion: Myeong-uk Choe, Creative Director of Isae'), Topclass, Chosun.com, February, http://topclass.chosun.com/board/view.asp?catecode=Q\&tnu=201002100011. Accessed 11 July 2017.

Clark, H. (2009), 'Fashioning “China Style” in the twenty-first century', in E. Paulicelli and H. Clark (eds), The Fabric of Cultures: Fashion, Identity and Globalization, Avingdon and New York: Routledge.

Condé Nast (2016), 'Korean fantasy’, Vogue Korea, January, pp. 194-205.

Craik, J. and Jansen, M. A. (2015), 'Constructing national fashion identities', International Journal of Fashion Studies, 2:1, pp. 3-8.

Globalization Committee (ed.) (1998), Segyehwa baekseo (Globalization White Paper), Seoul: Globalization Committee.

Gu, B. Son, H. Kang, N. Sim, G. and Yu, H. (1996), Segyehwa-wa minjokmunhwa-ui baljeon (Globalization and the Development of Korean National Culture, Seoul: Academy of Korean Studies.

Hanbok Advancement Centre (2015), Jiyeok hanbok munhwa contencheu josa mit sayeopmodel guchuk yeongu (The Report of Primary Investigation for the Promotion 
of Korean Culture and the Study on the Mid-and Long-Term Development Plan), Seoul: Hanbok Advancement Centre.

Hong, H. and Nam, M. (2010), 'Cheonyeon yeomsaek jepum-ui sijang sebunhwa mit sebun sijang-ui maeche iyong haedonggwa jeongbo tamsaek haedong' ('Natural dyed products market segmentation and usage of media and information sources among the segments'), Daehan gajeong hakhoeji (Journal of Korean Home Economics Studies), 48:8, pp. $113-28$.

Isae (2009), Philosophy - How to Make Clothes 2009-2010, catalogue. Seoul: Isae.

Isae (2011), Learning from Nature 2011-2012, catalogue. Seoul: Isae.

Jeong, J. (2000), 'Park Yun-su Korearism-eul jeanhanda' ('Park Yun-su proposes Koreanism'), Texjournal, January, pp. 112-14.

Jeong, K. (2016), interviewed by Yunah Lee, Seoul, 28 March.

Jo, B. (2013), 'Isae-wa G-Knit-ui chinhwangyeong donghaeng' ('The collaboration between Isae and G-Knit'), Korean High-Tech Textile Research Institute, November, http://www.koteri.re.kr/board/content.asp?board_id=koteri_notice\&ref=2578\&step=1 \&re level=\&page $=1$. Accessed 11 July 2017.

Jo, Y. (2013), 'Disaineo Kim Young-jin ui Hannamdong sari' ('Designer Kim Youngjin's house in Hannamdong', Yeoseong-jungang, October, 
http://mnbmagazine.joins.com/magazine/Narticle.asp?magazine=204\&articleId=IUSP

GKAHJAEBI4. Accessed 14 July 2017.

Kim, D. (1976), Hanguk boksiksa yeongu (Study of the History of Korean Dress),

Seoul: Asea-munhwa.

Kim, H. and Ha, J. (2010), 'Korean fashion crossovers', International Journal of Fashion Design, Technology and Education, 3:1, pp. 33-41.

Kim, I. (2008), 'Hangukjeok fashion disain-ui jeongcheseong-e daehan yeongu’ ('A study of the identity of Korean fashion design'), Hangbok munhwa hakhoeji (Journal of the Study of Hanbok Culture), 11:2, pp. 185-95.

Kim, M., Kim, H., and Cho, W. (2005), ‘Geundae ihu yeoseong saehwalhanbok-ui teukjing mit byeoncheon' ('Characteristic and transition of women's Saeng-Hwal-HanBok after Modern Korea'), Hanguk uisang desain hakhoeji (Journal of the Korean Fashion and Costume Design Association), 7:2, pp. 137-58.

Kim, Min-hui (2009), 'Hanbok-eun yeoja-ui majimak otteu cutireu yeyo: gaeleori-eseo hanbok jitneun yeoja, Kim Young-jin Tchai daepyo' ('Hanbok is the last haute couture for women:, Kim Young-jin, Tchai CEO, who is making hanbok in an art gallery'), Topclass, Chosun.com, February, http://topclass.chosun.com/board/view.asp? catecode=Q\&tnu=200902100001. Accessed 11 July 2017. 
Kim, Min-ja (2009), Hangukgeok fashion design-ui jedaum chatgi: jeontongmi-wa hyeondaejeok hwalyong-eul jungsimeuro (Discovering the Integrity of Korean Fashion Design: Focusing on the Contemporary Appropriation of Traditional Beauty), Seoul: Seoul National University Press.

Kim, S. (2001), 'Orientalism-ui jokswae: hankuk fashion jeongcheseong-ui dilema' ('Shackles of orientalism: The dilemma of Korean fashion identity', Disain munhwa bipyeong (Journal of Design Culture and Critique), 5, pp. 64-90.

Kim, U. (2006), 'Korean beauty’, Vogue Korea, May, pp. 115-20.

Kim, Y. (2016), interviewed by Yunah Lee, Seoul, 29 March.

Kwon, Y. and Lee, Y. (2015), 'Traditional aesthetic characteristics traced in South Korean contemporary fashion practice', Fashion Practice, 7: 2, pp. 153-74.

Leadbeater, C. (2012), 'New rules of Luxury', Collect: The International Art Fair for Contemporary Objects, London: Crafts Council, pp. 8-13.

Lee, J. (2012), 'Jeong Kyeong-a, CEO of Isae FnC daepyo: “jayeonjuui yeomsaek sojae-ro chinhwangyeong uiryu sijang dolpung ileukyeotjyo' ('Jeong Kyeong-a, CEO of Isae FnC: "We started the storm in the eco-fashion market with the use of natural dyes and fabrics"'), Economy Chosun, February, http://economyplus.chosun.com/special/special_view.php?boardName=C03\&t_num=6 002. Accessed 11 July 2017. 
Lee, M. and Kim, M. (2017), 'Fashioning identity and ideology: A cast study of a “quality” period K-drama Inspiring Generation', Fashion, Style and Popular Culture, 4:2, pp. 51-67.

Lee, Y. (2008), Pari-ro gan hanbok jaengi (Hanbok Designer Who Went to Paris), Seoul: Design House.

Lee, Y. (2009), Hankuk fashion munhwa sanyeop-ui hae-oe jinchul jiwon jeongchaek (Policy for the International Promotion of the Korean Fashion Culture Industry), Seoul: Korean Culture and Tourism Institute.

Leshkowich, A. M. and Jones, C. (2003) 'What happens when Asian chic becomes chic in Asia?', Fashion Theory, 7:3-4, pp. 281-300.

Ministry of Culture and Tourism (2001), Uri ot icheon-nyeon (Two Thousand Years of Korean Fashion and Culture), Seoul: Misul-munhwa.

Niessen, S., Leshkowich, A. M. and Jones, C. (eds) (2003), Re-Orienting Fashion: The Globalization of Asian Dress, Oxford and New York: Berg.

Paulicelli, E. and Clark, H. (eds) (2009), The Fabric of Cultures: Fashion, identity and Globalization, Avingdon and New York: Routledge. 
Ruhlen, R. (2003), ‘Korean alterations: Nationalism, social consciousness, and traditional clothing', in S. Niessen, A. M. Leshkowich and C. Jones (eds), ReOrienting Fashion: The Globalization of Asian Dress, Oxford and New York: Berg, pp. $117-37$.

Segre Reinach, S. S. (2011) 'National identities and international recognition', Fashion Theory, 15:2, pp. 267-72.

Shin, G. (2015), 'So much Seoul’, Vogue Korea, June, pp. 176-78.

Tchai Kim (2016), Official Press release, Seoul: Tchai Kim Young Jin. .

Tsui, C. (2013), 'From symbols to spirit: Changing conceptions of national identity in Chinese fashion', Fashion Theory, 17:5, pp. 579-604.

Yeom, H. (2001), 'Uri hanbok-ui stail-gwa mi: gaeryang hanbok trend-reul jungsimeuro' ('The style and beauty of Korean hanbok: Focusing on the trend of reformed hanbok'), Jeontong-gwa hyeondae (Tradition and Contemporary), 16, pp. 184-202.

Yim, S. (2015), 'geori-ro naon hanbok' ('Hanbok came to the street'), Vogue Korea, August, pp. 146-47.

Yoo, H. (2012), ‘fashion sanyeop-eseoui yulrijeok fashion: jisokganeunghan fashion-ui silcheon sarye' ('Ethical fashion in the fashion industry - Focusing on the actualization 
of sustainable fashion'), Hanguk fashion design hakhoeji (Journal of the Korean Society of Fashion Design), 12:2, pp. 39-57.

Yu, H. (1975), Hanguk boksiksa yeongu (Study on the History of Korea Dress), Seoul: Ehwa Women's University Press.

Yu, S. (1991), Hanguk boksiksa (History of Korean Dress), Seoul: Suhaksa.

\section{Contributor details}

Dr Yunah Lee is a senior lecturer in the History of Art and Design programme at the University of Brighton. Following obtaining her Ph.D. in the representation of modernity and national identity in design exhibitions of the British Design Council, Yunah's recent research investigates the development and potential of design history in Korea. She has been exploring notions of tradition and identity in the process of (re)writing Korean history post-1945 in the area of graphic design and fashion. She was a core steering member of the Arts and Humanities Research Council -funded network project 'Translating and Writing Modern Design Histories in East Asia for the Global World' (2012-14).

Contact: 10-11 Pavilion Parade, Brighton BN2 1RA, United Kingdom.

E-mail: Y.A.Lee@brighton.ac.uk

\section{Notes}

1 In this article, Korea refers to South Korea (the Republic of Korea) only. 2 Since the early publications on the history of Korean dress by Hui-kyeong $\mathrm{Yu}$ (1975) and Dong-wuk Kim (1976), most of the research and published works 
during the 1980s and 1990s have centred on establishing a chronological history of Korean dress until the end of the Joseon dynasty in the early twentieth century. It was based on then-newly discovered textiles and clothing from archaeological excavations and the subsequent conservation and cataloguing process. Colourful photographs, patterns and diagrams were published in the catalogues that accompanied exhibitions.

3 The slogan was widely used in policies and events promoting globalization in South Korea since the 1990s.

${ }^{4}$ Patent registration number: 30-0586290.

5 'Clay dying is a very complex, long and laborious process. First, the silk textile is dyed with the red fruit juice of Belladonna, rich with tannin. Clay with iron substances is added to the surface and left to dry out. Repeat this process several times. The fabric is then cured for six months outdoors, in the sun and wind, and eventually settles as the dark-coloured clay-dyed fabric' (from an Isae care leaflet, author's translation). 